\title{
DESAIN INTERFACE DETEKSI ARAH GERAK DENGAN GIS SEDERHANA
}

\section{DIRECTIONAL MOVEMENT DETECTION INTERFACE}

\author{
DESIGN WITH SIMPLE GIS
}

\author{
Anang Cahyono, Moh. Fakhrun Nizar \\ Ir. Nur Adi Siswandari, Okkie Puspitorini, ST \\ Jurusan Teknik Telekomunikasi, Politeknik Elektronika Negeri Surabaya \\ Institut Teknologi Sepuluh Nopember \\ Kampus ITS Keputih Sukolilo Surabaya 60111 \\ Tel : (+62) 031-5947280 Fax : (+62) 031-5946114
}

\begin{abstract}
ABSTRAK
Arah dan gerak benda dapat diketahui dari ouput kompas medan magnet bumi dan optocuopler. Kompas medan magnet bumi menghasilkan nilai tegangan tertentu pada sumbu $\mathrm{x}, \mathrm{y}$ dan $\mathrm{z}$ yang besarnya tidak sama untuk setiap arah pergeseran, sedangkan optocoupler menghasilkan tegangan untuk satu putaran roda. Dengan output tersebut, data dari sensor diintegrasikan dengan data dari peta pada Pc dan dengan konsep GIS sederhana akan dihasilkan suatu tampilan yang berupa posisi benda dan gerak benda pada wilayah peta dan juga dapat diperoleh informasi-informasi dari setiap penampakan pada peta.
\end{abstract}

\section{ABSTRAK}

The direction and movement of objetc can detected by using the output of $\mathbf{M M B}$ Compas and optocoupler. The MMB Compas field a specific output on the axis $x, y$, and $z$ with various value in every movement while optocoupler field power for of one circcle. With these output, data from the censor will be integrated with data from the map on the $P C$. Using the concept of simple GIS . we will get a display that discraibes position and movement of the object on the map area and any information needed of the shown map.

\section{PENDAHULUAN}

\subsection{Latar Belakang}

Pada era globalisasi ini, perkembangan teknologi informasi telah maju dengan pesat. Hal ini berimbas pada sistem komunikasi yang ada pada transportasi darat atau sering disebut sebagai sistem navigasi transportasi darat. Sistem navigasi transporatasi darat di negara-negara maju telah memakai jasa satelit GPS (Global Positioning systems) yang akan memberikan informasi dalam bentuk image (gambar) seperti peta dan pengemudi dapat melihat posisi kendaraannya pada peta tersebut dan mengetahui rute jalan yang dapat ditempuh.

Kompas medan magnet bumi dan optocoupler dapat digunakan untuk mengetahui arah dan gerak benda. Kedua sensor ini menghasilkan output digital, sehingga data arah dan gerak benda dapat diintegrasikan dengan data-data atau informasi yang lain dengan software dan hasilnya ditampilkan pada layar monitor sebuah PC.

Pada proyek akhir ini akan mengintegrasikan data dari kompas medan magnet bumi dan optocoupler dengan informasi yang berupa data geografik dari peta dengan konsep GIS (Geographic Information System) sederhana, sehingga diharapkan akan diperoleh informasi tentang posisi kendaraan dan gerak benda serta informasi-informasi yang lengkap dari penampakan yang ada pada peta. 


\subsection{Maksud dan Tujuan}

Tujuan dari pembuatan proyek akhir ini adalah untuk membuat suatu interface yang mampu mendeteksi arah gerak kendaraan dengan GIS sederhana, sehingga mambantu untuk memberikan informasi yang jelas dan menarik tentang posisi dan arah gerak dari kendaraan pada sistem navigasi transportasi darat.

\subsection{Batasan Masalah}

Arah gerak kendaraan hanya dapat di deteksi pada wilayah yang telah dipetakan. Pada proyek akhir ini wilayah yang dipetakan adalah wilayah ITS.

\section{PERENCANAAN DAN PEMBUATAN}

Didalam Proyek Akhir yang berjudul "DESAIN INTERFACE DETEKSI ARAH GERAK DENGAN GIS SEDERHANA “ yang terdiri atas perangkat lunak dan perangkat keras, tetapi disini ditekankan pada pembuatan perangkat lunaknya.

\subsection{Konfigurasi Sistem}

Konfigurasi sistem dapat dilihat pada blok diagram sistem di bawah ini :

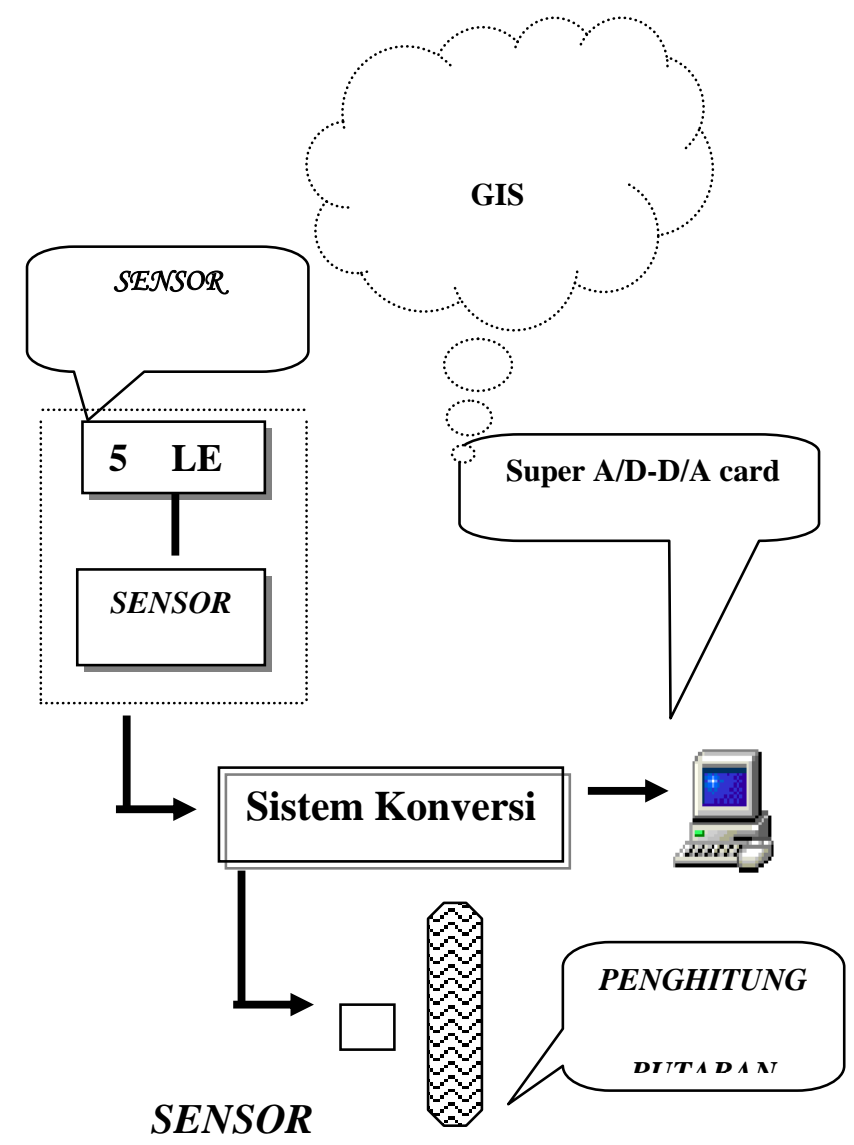

\subsubsection{Cara Kerja Sistem}

Urutan kerja sebagai berikut :

○ Sensor elektronik (Kompas MMB) 
Kompas ini menghasilkan data berupa tegangan pada sumbu $\mathrm{x}, \mathrm{y}$, dan $\mathrm{z}$ yang nilai tegangannya berbeda pada tiap pergeseran arah (dalam derajat)

o Sensor optocoupler

Sensor ini menghasilkan data berupa tegangan pada setiap satu kali putaran roda $(2 л R)$.

o Sistem Konversi Data.

Sistem konversi data adalah berupa card yang di letakkan pada slot ISA pada sebuah PC. Card A/D-DA 12 bit ini digunakan untuk mengkonversi sinyal analog dari sensor menjadi sinyal digital sehingga data dari sensor dapat diinterfacekan ke PC untuk diproses oleh software. Data dari dua buah sensor tersebut ditransmisikan ke super A/DD/A card melalui kabel DB-25. Data-data dari sensor dibaca oleh program sebagai tegangan masukan atau nilai desimal tegangan tersebut..

○ PC Note

PC note merupakan tempat program yang akan mengolah data. Data-data dari dua buah sensor akan diterjemahkan sebagai nilai arah dalam derajat dan pergerakan benda. Nilai arah dihasilakan dari kompas dan nilai pergerakan dihasilkan dari optocoupler. Datadata yang telah diterjemahkan diproses dengan data dari peta dan akan dihasilkan informasi tentang posisi kendaraan. Data-data dari sensor yang terkirim ke PC merupakan input program yang terjadi secara real time, sehingga arah gerak kendaraan juga akan dapat ditampilkan pada PC. Kendaraan diwakili oleh poniter kotak berwarna merah. Disamping informasi tersebut, juga dapat diketahui informasi lain tentang penampakan yang ada pada peta.

\subsection{Diagram Algoritma Program}

Algoritma program untuk memproses data adalah sebagai berikut :

- Input Inisialisasi dari keyboard

-Posisi awal $\left(\boldsymbol{X}_{\mathscr{\oplus}}, \mathrm{Y}_{\mathrm{o}}\right)$.

-Lingkaran Roda

- Membandingkan Input $\left(\boldsymbol{X}_{\oplus}, \mathrm{Y}_{\mathrm{o}}\right)$ dengan koordinat jalan pada peta

- Plot koordinat $\boldsymbol{X o}, \mathrm{Y}_{\mathrm{o}}$ pada peta

- Input perubahan dari dua sensor

-Arah adalah input dari 3 chanel input A/D yaitu ch 11(x), ch17(y) dan ch19(z).

-Gerak adalah input dari chanel 8.

- Konversi data

Data dari sensor diterjemahkan menjadi data yang berupa arah dengan pergeseran $22,5^{0}$ dan pergerakan dengan panjang sebesar keliling roda.

- Mengkalkulasi Xo, $\mathbf{Y}_{\mathrm{o}}$ dengan $\theta, \mathrm{r}$

Sehingga akan dihasilkan koordinat baru $(\mathrm{Xn}, \mathrm{Yn})$. Koordinat ini akan menjadi titik acuan untuk perubahan selanjutnya $(\mathrm{Xn}+1, \mathrm{Yn}+1)$.

- Membandingkan koordinat benda dengan koordinat jalan pada peta.

- Plot koordinat $\boldsymbol{X n}, \mathrm{Y}_{\mathrm{n}}$ pada peta.

- Dibawah ini adalah proses menghasilakan koordinat baru.

Dibawah ini adalah persamaan matematika yang digunkan untuk proses kalkulasi yang menghasilkan koordinat baru dan proses digitasi koordinat jalan. 


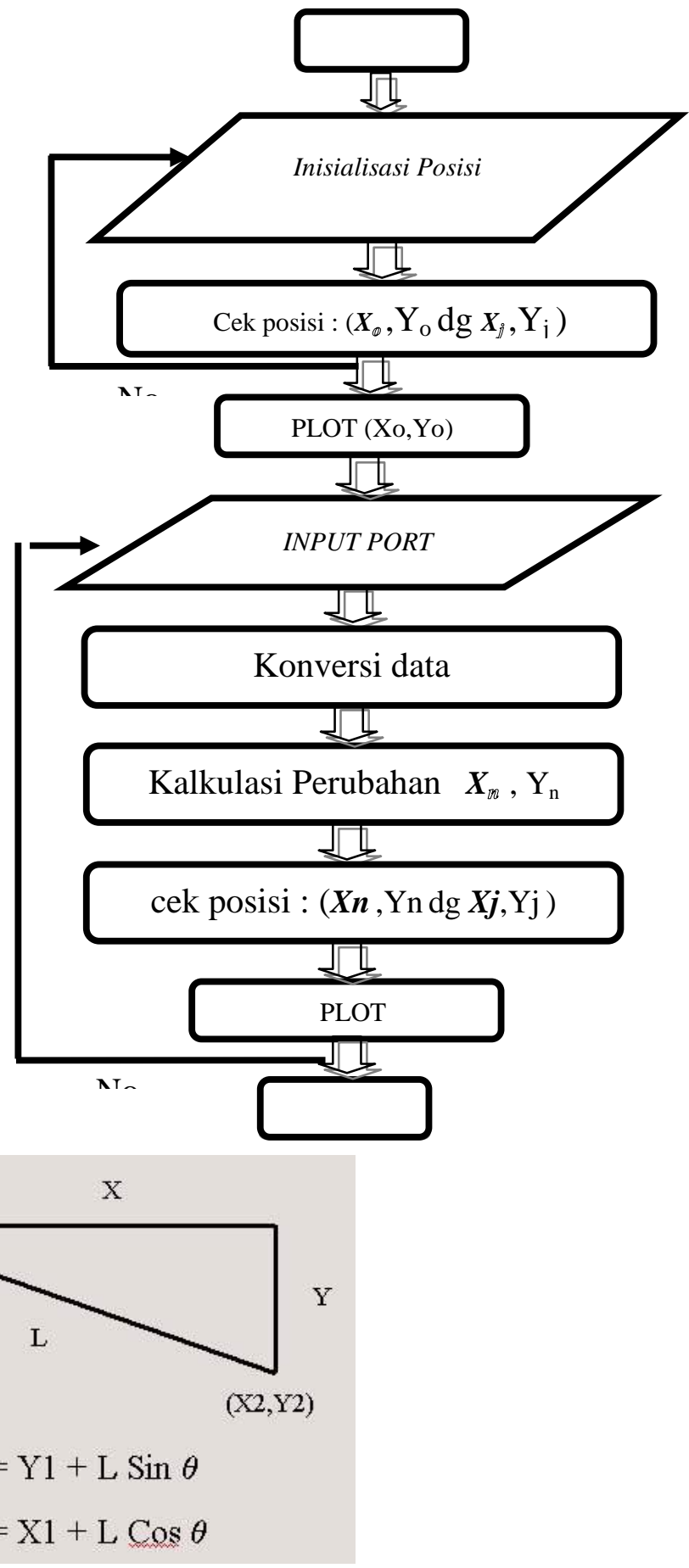

\section{ANALISA dan HASIL PROGRAM}

\subsection{PENGOPERASIAN PROGRAM}

Pengujian program ini dikhususkan pada pengolahan data yang akan menempatkan obyek pada area jalan yang ada pada peta. Penempatan ini dilakukan setalah proses membandingkan koordinat-koordinat jalan pada peta hasil digitasi dengan koordinat posisi awal benda yang di peroleh dari proses inisialiasi yang berupa masukan komponen koordinat $(\mathrm{X}, \mathrm{Y})$ atau membandingkan koordinat posisi baru suatu benda setelah bergerak dimana posisi baru tersebut diperoleh dari kalkulasi antara dua proses masukan yaitu masukan posisi awal dan masukan dari dua buah sensor yang berupa masukan gerak dan arah perubahan dengan acuan titik sebelumnya(posisi awal). Posisi baru akan menjadi titik acuan perubahan selanjutnya. 
Proses - proses yang terdapat pada program meliputi masukan data Inisialisasi, pengambilan data perpindahan benda dan penempatan obyek pada area jalan yang telah dipetakan.

\subsubsection{Masukan Inisialisasi}

Proses inisialisai ada dua hal yang harus diisikan yaitu pengisian posisi awal dan Panjang lingkaran roda. Pengisian data posisi awal dilakukan dengan memasukkan komponen koordianat $(\mathrm{X}, \mathrm{Y})$ pada kotak Edit1 dan Edit2 dan pengisian Lingkaran roda pada kotak Edit3 bila pengisian dipilih New. Pada proses pengisian ini, saat $\mathrm{x}=234$ dan $\mathrm{y}=200$ dan $\mathrm{L}=3$, maka tampil informasi bahwa koordinat tersebut tidak pada area jalan. Hal ini berarti proses pengisian posisi awal belum selesai atau pengguna harus mengisikan koordianat lain. Pada proses ini akan berualang terus sampai koordiant yang diisikan berada pada are jalan. Sedangkan bila dipilih default, pengisian dilkukan cukup sekali dan dilanjutkan proses selanjutnya yaitu penempatan obyek pada peta. Posisi defaul adala posisi benda pada koordinat $\mathrm{x}=182$ dan $\mathrm{y}=124$ dan $\mathrm{L}=4$.

\subsubsection{Pengambilan Data Perubahan}

Setelah prose inisialisasi, proses selanjutnya adalah pengambilan data perubahan dari dua buah sensor.Data -data dari sensor diinputkan melalui Chanel A/D yaitu chanel $11,8,13$, dan 8 . Data tersebut oleh program akan dibaca sebagai tegangan masukan dan desimal tegangan tersebut (12 bit). Data ini selanjutnya dikonversikan menjadi data arah dan gerak

Dibawah ini adalah data konversi tegngan X,Y dan Z menjadi Arah. Bila tidak ada sinyal yang masuk pada $\mathrm{AD} / \mathrm{DA}$ card, maka pada komputer akan tampil harga 10 dengan binernya 4950. Level 10 ini merupakan tegangan ambang maximal bagi AD/DA card.

\begin{tabular}{|l|l|l|l|l|}
\hline \multirow{2}{*}{ No } & \multicolumn{3}{|l|}{ Level Tegangan } & \multirow{2}{*}{$\begin{array}{l}\text { Arah } \\
\text { (derajat })\end{array}$} \\
\cline { 2 - 4 } & $\mathrm{x}$ & $\mathrm{y}$ & $\mathrm{z}$ & \\
\hline 1 & 5 & 0 & 1 & 0 \\
\hline 2 & 6 & 0 & 1 & 22.5 \\
\hline 3 & 6 & 1 & 1 & 45 \\
\hline 4 & 5 & 3 & 1 & 67.5 \\
\hline 5 & 5 & 5 & 1 & 90 \\
\hline 6 & 2 & 6 & 1 & 112.5 \\
\hline 7 & 1 & 6 & 1 & 135 \\
\hline 8 & 0 & 7 & 1 & 157.5 \\
\hline 9 & 0 & 7 & 0 & 180 \\
\hline 10 & 0 & 6 & 2 & 202.5 \\
\hline 11 & 0 & 5 & 4 & 225 \\
\hline 12 & 0 & 5 & 5 & 247.5 \\
\hline 13 & 0 & 4 & 5 & 270 \\
\hline 14 & 2 & 1 & 5 & 292.5 \\
\hline 15 & 3 & 0 & 4 & 315 \\
\hline 16 & 5 & 0 & 4 & 337.5 \\
\hline & & & & \\
\hline & & & & \\
\hline
\end{tabular}

Data tentang arah adalah pergeseran arah sebesar 22.5 sehingga terdapat 16 data arah. Sedangkan data dari optocoupler diterjemahkan sebagai satu panjang lingkaran roda bila tegangan yang dibaca adalah 2 atau $3 \mathrm{~V}$. Untuk $1 \mathrm{~V}$ panjang $\mathrm{L}=0$.

Data perubahan tersebut yang telah dikonversikan, dikalkulasikan dengan titik acuan perubahan, dimana titik acuan perubahan adalah titik ke N-1.

Pada pengujian data tersebut diperoleh dengan menggerakkan kompas agar dipelroleh sudut yang diinginkan dan mengkondisikan indikator loptocoupler(Led) menyala untuk asuatu gerak dan tidak menyala untuk kondisi benda diam. 


\subsubsection{Penempatan Obyek}

Setelah diperoleh koordinat baru maka proses selanjutnya adalah penempatan obyek pada area jalan di peta. Karena penempatan dilakukan dengan membandingkan koordinat obyek dengan koordinat-koordinat jalan yang berupa satu garis, sedangkan jalan pada peta berupa daerah diantara dua garis, dan toleransi penempatan adalah bila bagianbagian obyek (sudut-sudut Shape) masih berada pada area jalan, maka penempatan obyek akan tidak tepat benar pada area jalan. Penempatan obyek yang keluar dari area jalan akan ditandai dengan perubahan warna dari pointer (shape). Pointer akan tampak bergerak dari satu titik ke tiik lain. Hal ini disebabkan karena input dari sensor adalah secara real time.

Penempatan obyek juga akan diikuti dengan informasi-informasi tentang posisi obyek dan arah obyek berpindah. Selain informasi-informasi tersebut, pengguna juga dapat mengetahui tentang informasi-informasi dari penampakan yang ada pada peta dengan klik option penampakan yang diiginkan yang berada disebelah kanan.

\subsection{HAMBATAN}

-Proses penempatan obyek dilakukan dengan membandingkan koordinat-koordinat obyek dengan koordinat-koordinat hasil digitasi jalan. Data digitasi jalan adalah berupa kumpulan koordinat titik sepanjang lintasan jalan yang membentuk garis lurus, sedangkan lintasan jalan pada peta adalah berupa area

diantara dua garis dan juga dapat berupa lintasan yang melingkar, sehingga proses penempatan obyek pada posisi tertentu dari suatu lintasan jalan akan mengalami

kesalahan yaitu obyek yang seharusnya tidak ditampakkan akan tetapi ditampakkan atau sebaliknya.

-Mengarahkan obyek agar selulu berada pada area jalan.

\section{KESIMPULAN DAN SARAN \\ 4.1 KESIMPULAN}

Setelah dilakukan pemahaman teori penunjang serta pengujian dan evaluasi perangkat lunak dalam tugas akhir ini maka dapat diambil beberapa kesimpulan, antara lain:

1. Dari hasil desain interface deteksi arah gerak dengan GIS sederhana dapat dibuktikan bahwa dengan memamfaatkan kompas medan magnet bumi, informasi tentang posisi kendaraan pada kedudukan geografik bumi dapat diketahui.

2. Input yang berasal dari ssensor terjadi secara real time, sehingga arah gerak benda dapt dipantau dari layar monitor PC.

3. Arah yang dapt dideteksi adalah arah dengan pergeseran $22.5^{\circ}$, sehingga hanya ada 16 arah yang yang diperoleh dari konpas.

\subsection{SARAN}

Untuk penyempurnaan alat ini selanjutnya, maka yang perlu diperhatikan adalah sebagai berikut :

1. Untuk pengembangan selanjutnya perangkat lunak ini sebaiknya ditingkatkan fasilitasnya agar dapat diakses secara langsung melalui internat. Perangkat lunak yang dikembangkan dengan $\mathrm{C}++$ Buider ini sudah dirancang untuk pengembangan ke hal tersebut.

2. Data pada setiap penampakan pada Peta ITS yang di tampilkan masih sangat sedikit. Oleh karena itu agar perangkat lunak ini dapat dimamfaatkan oleh semua orang diperlukan bantuan semua pihak yang berkenan untuk masukkan berbangai data yang diperlukan guna menambah informasi dan wawasan tentang kampus ITS. 


\section{DAFTAR PUSTAKA}

1) Djoko Pramono, Mudah Menguasi C++ Builder, PT Elex Media Komputindo, 1997

2) John Miano,Tom Cabanski, Harold Howe, How-to Borland C++ Builder, 1997

3) Ir Nanang syahroni, Diktat Komunikasi data, EEPIS, 1998

4) http//www.esri.com 